\title{
Cardiopulmonary Exercise Testing and Impedance Cardiography in The Assessment of Exercise Capacity of Patients with Coronary Artery Disease
}

Małgorzata Kurpaska ( $\square$ mkurpaska@wim.mil.pl )

Military Institute of Medicine

Paweł Krzesiński

Military Institute of Medicine

Grzegorz Gielerak Prof

Military Institute of Medicine

Karina Gołębiewska

Military Institute of Medicine

Katarzyna Piotrowicz

Military Institute of Medicine

\section{Research Article}

Keywords: hemodynamic parameters, coronary artery disease, exercise capacity, cardiac rehabilitation

Posted Date: June 14th, 2021

DOI: https://doi.org/10.21203/rs.3.rs-587245/v1

License: (c) (1) This work is licensed under a Creative Commons Attribution 4.0 International License. Read Full License 


\section{Abstract \\ Background}

Patients with coronary artery disease (CAD) are characterized by different levels of physical capacity, which depends not only on the anatomical advancement of atherosclerosis, but also on the individual cardiovascular hemodynamic response to exercise. The aim of this study was to evaluate the relationship between parameters of exercise capacity assessed via cardiopulmonary exercise testing (CPET) and impedance cardiography (ICG) hemodynamics in patients with CAD.

\section{Methods}

Exercise capacity was assessed in 54 patients with CAD (41 men, aged $59.5 \pm 8.6$ years) within 6 weeks after revascularization by means of oxygen uptake $\left(\mathrm{VO}_{2}\right)$, assessed via CPET, and hemodynamic parameters (heart rate (HR), stroke volume (SV), cardiac output (CO), left cardiac work index (LCWi)), measured by ICG. Correlations between these parameters at anaerobic threshold (AT) and at the peak of exercise as well as their changes ( $\Delta$ peak-rest, $\Delta$ peak-AT) were evaluated.

\section{Results}

A large proportion of patients exhibited reduced exercise capacity, with $63 \%$ not reaching $80 \%$ of predicted peak $\mathrm{VO}_{2}$. Clinically relevant correlations were noted between the absolute peak values of $\mathrm{VO}_{2}$ vs. $\mathrm{HR}, \mathrm{VO}_{2}$ vs. $\mathrm{CO}$, and $\mathrm{VO}_{2}$ vs. LCWi $(\mathrm{R}=0.45, \mathrm{p}=0.0005 ; \mathrm{R}=0.33, \mathrm{p}=0.015$; and $\mathrm{R}=0.40, \mathrm{p}=0.003$, respectively). There was no correlation between $\mathrm{AT} \mathrm{VO}_{2}$ and hemodynamic parameters at the AT time point. Furthermore $\Delta \mathrm{VO}_{2}($ peak-AT) correlated with $\Delta \mathrm{HR}$ (peak-AT), $\triangle \mathrm{CO}$ (peak-AT) and $\triangle \mathrm{LCWi}$ (peak-AT) $\left(\mathrm{R}=0.52, \mathrm{p}<0.0001, \mathrm{R}=0.49, \mathrm{p}=0.0001\right.$; and $\mathrm{R}=0.49, \mathrm{p}=0.0001$, respectively). $\Delta \mathrm{VO}_{2}$ (peak-rest) correlated with $\Delta \mathrm{HR}$ (peak-rest), $\Delta \mathrm{CO}$ (peak-rest), and $\Delta \mathrm{LCWi}$ (peak-rest) $(\mathrm{R}=0.47, \mathrm{p}<0.0001 ; \mathrm{R}=0.41, \mathrm{p}$ $=0.002$; and $\mathrm{R}=0.43, \mathrm{p}=0.001$, respectively).

\section{Conclusion}

ICG is a reliable method of assessing the cardiovascular response to exercise in patients with CAD. Some ICG parameters show definite correlations with parameters of cardiovascular capacity of proven clinical utility, such as peak $\mathrm{VO}_{2}$.

\section{Introduction}

Exercise capacity plays an important role in risk stratification in patients with coronary artery disease (CAD) $[1,2]$, as it is a potentially stronger predictor of mortality than other risk factors, such as smoking, 
hypertension, high cholesterol levels, and type 2 diabetes mellitus [3]. Moreover, patients with comparable exercise capacities have comparable mortality risks, irrespective of their baseline coronary revascularization status [4].

CAD patients may have various levels of exercise capacity, which is dependent not only on the severity of atherosclerosis but also on potential comorbidities and the individual cardiovascular hemodynamic response to exercise. The mechanism of exercise-induced increase in cardiac output (CO) may vary depending on heart rate (HR) and/or stroke volume (SV) alterations [5, 6]. Optimally, both components should increase simultaneously [6], with any deviations from this principle suggesting cardiovascular dysfunction. For instance, abnormal SV profile alterations during exercise in CAD patients who have undergone successful revascularization suggest microcirculatory dysfunction [7] and may affect the course and outcome of cardiac rehabilitation.

In everyday practice, the gold standard in noninvasive assessment of exercise capacity is cardiopulmonary exercise testing (CPET), which measures dynamic changes in such parameters as oxygen uptake $\left(\mathrm{VO}_{2}\right), \mathrm{HR}$, and oxygen pulse $\left(\mathrm{O}_{2}\right.$ Pulse $)[7,8,9,10]$. However, these parameters are only indirect indicators of hemodynamic adaptation to exercise. Moreover, these parameters may be confounded by concomitant respiratory and metabolic abnormalities. Impedance cardiography (ICG) is a novel noninvasive diagnostic technique for analyzing changes in $\mathrm{CO}$ and its components (HR and SV) during exercise testing. Preliminary research showed that ICG is a simple, accurate, and reproducible method of measuring these parameters over a wide range of workloads [11]. Our team's previous studies $[12,13]$ demonstrated the usefulness of ICG in assessing the hemodynamic response to exercise in a group of hypertensive patients, by showing that ICG may complement traditional exercise testing and reveal an impaired hemodynamic response to exercise as a cause of unexplained dyspnea.

Therefore, the purpose of this study was to evaluate the relationship between the parameters of exercise capacity assessed via CPET and ICG hemodynamics in CAD patients who were candidates for cardiac rehabilitation.

\section{Methods}

Study group. The study enrolled 77 CAD patients of both sexes, aged 30-80 years, who were candidates for phase II cardiac rehabilitation, and had undergone coronary angioplasty or coronary artery bypass grafting within 6 weeks prior to recruitment. The exclusion criteria were significant coronary artery stenosis; confirmed secondary hypertension; chronic kidney disease with the estimated glomerular filtration rate $($ eGFR $)<30 \mathrm{~mL} / \mathrm{min} / 1.73 \mathrm{~m}^{2}$ calculated based on the MDRD equation; clinically important valvular heart disease; significant arrhythmias; non-sinus rhythm (including permanent pacemakers); body mass index $(\mathrm{BMI})>40 \mathrm{~kg} / \mathrm{m}^{2}$; polyneuropathy; exercise-limiting peripheral artery disease and/or skeletal muscle disorders; psychiatric conditions preventing the patient's full cooperation; and exacerbated lung conditions (asthma, chronic obstructive pulmonary disease (COPD)). 
Clinical examination. The clinical examination included past medical history; drug history; current symptoms, particularly exercise tolerance (fatigue, dyspnea on exertion and at rest, chest pain); and smoking status. Physical examination included office measurements of heart rate (HR), systolic blood pressure (SBP), and diastolic blood pressure (DBP), and anthropometric measurements (height, weight, $\mathrm{BMI})$. Laboratory tests were conducted on fasting peripheral venous blood samples collected in the morning (7:00-8:30 am), before CPET. The eGFR was calculated according to the MDRD equation.

Echocardiography. Echocardiographic examinations were conducted with a Vivid S6 ultrasound system (GE Medical System, Wauwatosa, WI, USA) following revascularization and no more than 6 weeks prior to recruitment. The examination included standard parasternal, apical, and subcostal views, and assessed cardiac chamber size, valvular structure and function, left ventricular ejection fraction (LVEF) measured via the Simpson method, diastolic function, and evidence of left ventricular hypertrophy. Heart failure (HF) was diagnosed based on current guidelines [14].

Cardiopulmonary exercise testing. Each patient underwent CPET in the morning, between 9:00 and 11:00 am, following the morning dose of their medications. An Ergoselect cycle ergometer (Geratherm Respiratory $\mathrm{GmbH}$; Germany) was used, with individualized ramp protocols set to achieve the predicted load within $10 \mathrm{~min}$. Oxygen and carbon dioxide sensors and the flow sensor (Ergoflow, Geratherm Respiratory GmbH; Germany) were calibrated before each test. Prior to CPET, each patient underwent resting spirometry. Each patient underwent maximum CPET, which was stopped if severe symptoms (fatigue, dyspnea) appeared or at the patient's request [15]. Throughout each CPET session, breath-bybreath gas exchange was monitored via a Geratherm Ergostik system (Geratherm Respiratory GmbH; Germany). The following parameters were analyzed: $\mathrm{VO}_{2}[\mathrm{~mL} / \mathrm{kg} / \mathrm{min}]$, workload [W], $\mathrm{O}_{2}$ Pulse $[\mathrm{mL} / \mathrm{min}]$, relationship between oxygen uptake and work rate $\left(\mathrm{VO}_{2} / \mathrm{WR}\right)[\mathrm{mL} / \mathrm{min} / \mathrm{W}]$, ventilatory efficiency (ventilation-to-carbon dioxide output, $\mathrm{VE} / \mathrm{VCO}_{2}$ slope) during exercise, respiratory exchange ratio (RER). These parameters were analyzed at rest prior to CPET, at the anaerobic threshold (AT) and at peakVO ${ }_{2}$. PeakVO ${ }_{2}$ was expressed as the highest mean oxygen consumption over the last 30 seconds of exercise. The AT was determined noninvasively, with the V-slope method after CPET conclusion [16]. Workload, $\mathrm{VO}_{2}$ and $\mathrm{O}_{2}$ Pulse were expressed as percentage of their respective predicted values at peak exercise [peak $\%$ pred]. The predicted value of $\mathrm{VO}_{2}$ (pred $\mathrm{VO}_{2}$ ) was estimated based on Wasserman's equation. [16]. $\mathrm{VE} / \mathrm{VCO}_{2}$ slope was calculated with a regression formula Microsoft Excel. $\mathrm{O}_{2}$ Pulse was calculated as the quotient of $\mathrm{VO}_{2}$ and $\mathrm{HR}$. The changes in $\mathrm{VO}_{2}\left(\Delta \mathrm{VO}_{2}\right)$ between the value at rest and both at $\mathrm{AT}$ and at peak exercise (peak-rest, peak-AT) were calculated. The RER, defined as $\mathrm{VCO}_{2} / \mathrm{VO}_{2}$, represented the highest mean value from the last 30 seconds during the final stage of CPET.

Exercise impedance cardiography. Exercise ICG was conducted with the use of a PhysioFlow monitor (Manatec, Paris, France). The methods employed during ICG were described in our earlier paper [12]. The device offered beat-to-beat acquisition of the following parameters: HR [bpm], SV [mL], CO [mL/min], and left cardiac work index $\left(\mathrm{LCWi}\left[\mathrm{kg} \bullet \mathrm{m} / \mathrm{m}^{2}\right]\right)$, with the last one defined as the estimated energy requirement of the left ventricle to eject blood against the aortic pressure. As it was done in the case of CPET 
parameters, we calculated the changes in these parameters between their values at rest and both at AT and peak exercise (peak-rest, peak-AT).

Statistical analysis. Obtained results were analyzed statistically with Statistica 12.0 software (StatSoft Inc., Tulsa, OK, USA). Data distribution and normality were assessed visually and with the KolmogorovSmirnov test. Continuous variables were presented as means \pm standard deviation (SD), whereas qualitative variables were presented as absolute and relative frequencies (percentages). Relationships between absolute $\mathrm{LVEF}, \mathrm{VO}_{2}$, and hemodynamic parameters at $\mathrm{AT}$ and at peak exercise on one side and the changes in the analyzed exercise parameters (peak-rest, peak-AT) on the other were analyzed with Pearson/Spearman's correlation coefficients. The $p$-value of $<0.05$ was considered statistically significant.

\section{Results}

A total of 77 patients were included in the study. However, only the results of those 54 patients whose RER exceeded 1.05 (i.e. who completed maximum CPET) were ultimately analyzed. Their baseline characteristics are presented in Table 1. Nearly a half of the study group reported limited exercise tolerance, most commonly in the form of dyspnea. The vast majority of patients had preserved LVEF (mean LVEF of $54 \%$ ), with $22.3 \%$ of patients diagnosed with HF. The most common concomitant conditions potentially affecting exercise tolerance were hypertension, smoking, and diabetes mellitus (reported by $72.2 \%, 53.7 \%$, and $20.4 \%$ of patients, respectively). All patients were receiving optimal medical treatment for CAD. 
Table 1

Baseline characteristics.

\begin{tabular}{|c|c|}
\hline Variable & study group $(n=54)$ \\
\hline men, n (\%) & $41(75.9)$ \\
\hline age (years), mean $\pm S D$ & $59.5 \pm 8.6$ \\
\hline $\mathrm{SBP}(\mathrm{mmHg})$, mean $\pm \mathrm{SD}$ & $133.4 \pm 18.6$ \\
\hline $\mathrm{DBP}(\mathrm{mmHg})$, mean $\pm \mathrm{SD}$ & $77.5 \pm 11.1$ \\
\hline $\mathrm{HR}(\mathrm{bpm})$, mean $\pm \mathrm{SD}$ & $66.8 \pm 11.9$ \\
\hline $\operatorname{BMI}\left(\mathrm{kg} / \mathrm{m}^{2}\right)$, mean $\pm \mathrm{SD}$ & $28.3 \pm 4.1$ \\
\hline creatinine $(\mathrm{mg} / \mathrm{dL})$, mean $\pm \mathrm{SD}$ & $0.92 \pm 0.20$ \\
\hline eGFR $<60 \mathrm{~mL} / \mathrm{min} / 1.73 \mathrm{~m}^{2}, \mathrm{n}(\%)$ & $3(5.6)$ \\
\hline LVEF (\%), mean \pm SD & $54.5 \pm 7.8$ \\
\hline LVEF < 50\%, n (\%) & $11(20.4)$ \\
\hline HFpEF, n (\%) & $3(5.6)$ \\
\hline HFmrEF, n (\%) & $4(7.4)$ \\
\hline HFrEF, n (\%) & $5(9.3)$ \\
\hline hypertension, n (\%) & $39(72.2)$ \\
\hline diabetes, n (\%) & $11(20.4)$ \\
\hline hypercholesterolemia, n (\%) & $45(83.3)$ \\
\hline COPD, n (\%) & $3(5.6)$ \\
\hline atrial fibrillation paroxysmal/non-paroxysmal, n (\%) & $5(9.3) / 0(0.0)$ \\
\hline smoking, n (\%) & $29(53.7)$ \\
\hline \multicolumn{2}{|l|}{ Symptoms } \\
\hline reduced exercise tolerance, $\mathrm{n}(\%)$ & $25(46.5)$ \\
\hline dyspnea during exercise, n (\%) & $14(25.9)$ \\
\hline dyspnea at rest, n (\%) & $3(5.6)$ \\
\hline \multicolumn{2}{|l|}{ Pharmacotherapy } \\
\hline ACEI, n (\%) & $53(98.2)$ \\
\hline ARB, n (\%) & $1(1.9)$ \\
\hline
\end{tabular}




\begin{tabular}{|ll|}
\hline Variable & study group $(\mathbf{n}=\mathbf{5 4})$ \\
\hline $\mathrm{BB}, \mathrm{n}(\%)$ & $51(94.4)$ \\
\hline diuretic, $\mathrm{n}(\%)$ & $20(37.0)$ \\
\hline $\mathrm{CB}, \mathrm{n}(\%)$ & $11(20.4)$ \\
\hline $\mathrm{MRA}, \mathrm{n}(\%)$ & $3(5.6)$ \\
\hline statin, $\mathrm{n}(\%)$ & $53(98.2)$ \\
\hline antiplatelet, $\mathrm{n}(\%)$ & $54(100)$ \\
\hline $\begin{array}{l}\text { ACEI - angiotensin converting enzyme inhibitor; ARB - angiotensin receptor blocker; BB - beta bloker; } \\
\text { BMI - body mass index; CB - calcium canal blocker; COPD - chronic obstructive pulmonary disease; } \\
\text { DBP - diastolic blood pressure; eGFR - estimated glomerular filtration rate; HFmrEF - heart failure with } \\
\text { a mid-range ejection fraction; HFpEF - heart failure with preserved ejection fraction; HFrEF - heart } \\
\text { failure with a reduced ejection fraction; HR - heart rate; LVEF- left ventricular ejection fraction; LVH - } \\
\text { left ventricular hypertrophy; MRA - mineralocorticoid receptor antagonists; NTproBNP - N-terminal pro- } \\
\text { B-type brain natriuretic peptide; SBP - systolic blood pressure; SD - standard deviation }\end{array}$ \\
\hline
\end{tabular}

\section{Cardiopulmonary exercise test and impedance cardiography}

Exercise capacity and hemodynamic parameters are presented in Table 2. Most patients exhibited low exercise capacity, with $63 \%$ of patients failing to exceed $80 \%$ of their predicted peak $\mathrm{VO}_{2}$. The $\mathrm{VO}_{2} / \mathrm{WR}$ values were generally low; however, $\mathrm{VE} / \mathrm{VCO}_{2}$ slope was normal in most patients. The increase in $\mathrm{VO}_{2}$ from AT to peak exercise was much lower than the increase in $\mathrm{VO}_{2}$ from its rest value to that at AT. 
Table 2

Evaluation of exercise capacity and cardiovascular function via cardiopulmonary exercise testing with a simultaneous hemodynamic assessment via impedance cardiography

study group $(n=54)$

\section{CPET}

peakworkload $(W)$, mean $\pm S D$

$\%$ pred. peak workload (\%), mean \pm SD

$\mathrm{VO}_{2} / \mathrm{WR}(\mathrm{mL} / \mathrm{min} / \mathrm{W})$, mean $\pm \mathrm{SD}$

peak $\mathrm{O}_{2}$ pulse $(\mathrm{mL} /$ beat $)$, mean $\pm \mathrm{SD}$

$\%$ pred. peak $\mathrm{O}_{2}$ pulse (\%), mean $\pm \mathrm{SD}$

VE $/ \mathrm{VCO}_{2}$ Slope, mean $\pm \mathrm{SD}$

restVO ${ }_{2}(\mathrm{~mL} / \mathrm{min} / \mathrm{kg})$, mean $\pm \mathrm{SD}$

AT $\mathrm{VO}_{2}(\mathrm{~mL} / \mathrm{min} / \mathrm{kg})$, mean $\pm \mathrm{SD}$

peak $\mathrm{VO}_{2}(\mathrm{~mL} / \mathrm{min} / \mathrm{kg})$, mean $\pm \mathrm{SD}$

$\%$ pred. peak $\mathrm{VO}_{2}(\%)$, mean $\pm \mathrm{SD}$

$\%$ pred. peak $\mathrm{VO}_{2}<80 \% \mathrm{VO}_{2}$ of predicted value, $\mathrm{n}(\%)$

$\Delta \mathrm{VO}_{2}$ (peak-rest) $(\mathrm{mL} / \mathrm{min} / \mathrm{kg})$, mean $\pm \mathrm{SD}$

$\Delta \mathrm{VO}_{2}($ peak $-\mathrm{AT})(\mathrm{mL} / \mathrm{min} / \mathrm{kg})$, mean $\pm \mathrm{SD}$

ICG

rest HR (bpm), mean \pm SD

AT HR (bpm), mean \pm SD

peak HR (bpm), mean \pm SD

$\Delta \mathrm{HR}$ (peak-rest) (bpm), mean $\pm \mathrm{SD}$

$\Delta \mathrm{HR}$ (peak-AT) (bpm), mean $\pm \mathrm{SD}$

rest $S V(m L)$, mean $\pm S D$

AT SV $(\mathrm{mL})$, mean \pm SD

peak SV $(\mathrm{mL})$, mean $\pm \mathrm{SD}$

$\Delta S V$ (peak-rest) $(\mathrm{mL})$, mean $\pm \mathrm{SD}$
$129.4 \pm 36.8$

$82.8 \pm 12.9$

$9.7 \pm 1.5$

$14.5 \pm 10.5$

$97.9 \pm 23.0$

$28.7 \pm 4.4$

$3.6 \pm 0.6$

$13.1 \pm 2.3$

$18.2 \pm 4.3$

$74.2 \pm 13.5$

34 (63.0)

$14.7 \pm 4.1$

$5.1 \pm 3.0$

$67.7 \pm 12.1$

$97.5 \pm 12.2$

$125.6 \pm 18.3$

$57.9 \pm 16.9$

$28.1 \pm 13.1$

$80.1 \pm 17.4$

$107.0 \pm 22.4$

$116.4 \pm 27.6$

$36.3 \pm 21.9$ 


\begin{tabular}{|c|c|}
\hline$\Delta S V($ peak-AT $)(m L)$, mean $\pm S D$ & $9.4 \pm 16.5$ \\
\hline rest $\mathrm{CO}(\mathrm{L} / \mathrm{min})$, mean $\pm \mathrm{SD}$ & $5.4 \pm 1.2$ \\
\hline AT CO $(\mathrm{L} / \mathrm{min})$, mean $\pm \mathrm{SD}$ & $10.4 \pm 2.1$ \\
\hline peak $\mathrm{CO}(\mathrm{L} / \mathrm{min})$, mean $\pm \mathrm{SD}$ & $14.5 \pm 3.4$ \\
\hline$\Delta \mathrm{CO}$ (peak-rest $)(\mathrm{L} / \mathrm{min})$, mean $\pm \mathrm{SD}$ & $9.1 \pm 3.1$ \\
\hline$\Delta \mathrm{CO}($ peak-AT $)(\mathrm{L} / \mathrm{min})$, mean $\pm \mathrm{SD}$ & $4.1 \pm 2.4$ \\
\hline restLCWi $\left(\mathrm{kg}{ }^{\star} \mathrm{m} / \mathrm{m}^{2}\right)$, mean $\pm \mathrm{SD}$ & $3.3 \pm 1.0$ \\
\hline AT LCWi $\left(\mathrm{kg}{ }^{\star} \mathrm{m} / \mathrm{m}^{2}\right.$, mean $\pm \mathrm{SD}$ & $7.2 \pm 2.2$ \\
\hline peakLCWi $\left(\mathrm{kg}^{\star} \mathrm{m} / \mathrm{m}^{2}\right)$, mean $\pm \mathrm{SD}$ & $12.1 \pm 4.2$ \\
\hline$\Delta \mathrm{LCWi}($ peak-rest $)\left(\mathrm{kg}{ }^{\star} \mathrm{m} / \mathrm{m}^{2}\right)$, mean $\pm \mathrm{SD}$ & $8.8 \pm 3.9$ \\
\hline$\Delta \mathrm{LCWi}($ peak $-\mathrm{AT})\left(\mathrm{kg}{ }^{\star} \mathrm{m} / \mathrm{m}^{2}\right)$, mean $\pm \mathrm{SD}$ & $4.9 \pm 3.1$ \\
\hline
\end{tabular}

AT - value at anaerobic threshold; \%pred. AT - percentage of predictive value at anaerobic threshold; peak - value at peak exercise; \%pred. peak - percentage of predictive peak value; $\mathrm{CO}$ - cardiac output; CPET - cardiopulmonary exercise test; HR - heart rate; ICG - impedance cardiography; LCWi - left cardiac work index; SD - standard deviation; SV - stroke volume; VE/ $/ \mathrm{CO}_{2}$ - ventilatory equivalent for carbon dioxide production; $\mathrm{VO}_{2}$ - oxygen uptake; WR - work rate; $\Delta$ - changes in parameter between its measurements at rest, at peak exercise, and at the anaerobic threshold

Throughout the exercise period (peak-rest), all patients demonstrated an increase in CO, both its components (SV and HR), and LCWi (Fig. 1). The increase in HR and CO that occurred after AT (peak-AT) constituted nearly a half of the total increase in these parameter values during the exercise period, whereas the increase in SV after AT was minimal. Conversely, LCWi increased more notably during the period after AT than at the beginning of exercise (AT-rest). As many as 17 patients (31.5\%) showed a decrease in SV from the value at the AT to that at peak exercise, with a decrease in CO during the same period observed in 2 patients (3.7\%). However, there were no cases of a decrease in HR between these time points.

The peak values of individual hemodynamic parameters were very widely distributed, with the broadest ranges observed for peak SV (median $114 \mathrm{~mL}$; minimum $57 \%$ of median; maximum 201\% of median), peak LCWi $\left(11.8 \mathrm{~kg} \cdot \mathrm{m} / \mathrm{m}^{2} ; 40 \% ; 197 \%\right.$, respectively), and peak VO $2(18.0 \mathrm{~mL} / \mathrm{min} / \mathrm{kg} ; 39 \% ; 168 \%$, respectively). The distribution range was somewhat narrower for peak CO (median $14.4 \mathrm{~mL} / \mathrm{min} ; 58 \%$; $153 \%$, respectively), and it was the narrowest for peak HR (median 128 bpm; 67\%; 130\%, respectively).

\section{Correlations between $\mathrm{VO}_{2}$ values and those of selected hemodynamic parameters}


Table 3 shows the correlations between absolute $\mathrm{VO}_{2}$ values and relative $\mathrm{VO}_{2}$ changes at various time points during exercise and the values of selected hemodynamic parameters. The evaluated group of patients demonstrated clinically relevant correlations between absolute values of peak $\mathrm{VO}_{2}$ and peak $\mathrm{HR}$, peak $\mathrm{VO}_{2}$ and peak $\mathrm{CO}$, and peakVO $\mathrm{V}_{2}$ and peak LCWi. There was no correlation between $\mathrm{VO}_{2}$ values at AT and hemodynamic parameter values at AT.

Table 3

Correlations between the absolute values of $\mathrm{VO}_{2}$ at various CPET time points and those of selected hemodynamic parameters, as well as correlations between the relative changes in $\mathrm{VO}_{2}$ at various CPET time points and those in selected hemodynamic parameters

\begin{tabular}{|c|c|c|c|c|}
\hline & AT HR (bpm) & AT SV (mL) & AT CO (L/min) & $\begin{array}{l}\text { AT LCWi } \\
\left(\mathrm{kg}^{*} \mathrm{~m} / \mathrm{m}^{2}\right)\end{array}$ \\
\hline AT VO ${ }_{2}(\mathrm{~mL} / \mathrm{min} / \mathrm{kg})$ & 0.17 & 0.05 & 0.15 & 0.22 \\
\hline \multirow[t]{2}{*}{$\mathrm{p}$} & 0.221 & 0.720 & 0.270 & 0.102 \\
\hline & peak HR (bpm) & peak SV (mL) & peak CO (L/min) & $\begin{array}{l}\text { peakLCWi } \\
\left(\mathrm{kg}^{\star} \mathrm{m} / \mathrm{m}^{2}\right)\end{array}$ \\
\hline peakVO $_{2}(\mathrm{~mL} / \mathrm{min} / \mathrm{kg})$ & 0.45 & 0.03 & 0.33 & 0.40 \\
\hline \multirow[t]{2}{*}{$\mathrm{p}$} & 0.0005 & 0.835 & 0.015 & 0.003 \\
\hline & $\begin{array}{l}\Delta \mathrm{HR}(\text { peak-rest }) \\
(\mathrm{bpm})\end{array}$ & $\begin{array}{l}\Delta S V \text { (peak-rest) } \\
(\mathrm{mL})\end{array}$ & $\begin{array}{l}\triangle \mathrm{CO} \text { (peak-rest) } \\
(\mathrm{L} / \mathrm{min})\end{array}$ & 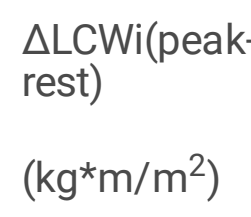 \\
\hline $\begin{array}{l}\Delta \mathrm{VO}_{2} \text { (peak-rest) } \\
(\mathrm{mL} / \mathrm{min} / \mathrm{kg})\end{array}$ & 0.47 & 0.11 & 0.41 & 0.43 \\
\hline \multirow[t]{2}{*}{$\mathrm{p}$} & $<0.0001$ & 0.429 & 0.002 & 0.001 \\
\hline & $\begin{array}{l}\Delta \mathrm{HR}(\text { peak-AT }) \\
(\mathrm{bpm})\end{array}$ & $\begin{array}{l}\Delta S V(\text { peak-AT }) \\
(\mathrm{mL})\end{array}$ & $\begin{array}{l}\Delta \mathrm{CO}(\text { peak-AT }) \\
(\mathrm{L} / \mathrm{min})\end{array}$ & $\begin{array}{l}\triangle \mathrm{LCWi} \text { (peak } \\
\text { AT }) \\
\left(\mathrm{kg} \mathrm{m}^{\star} \mathrm{m} \mathrm{m}^{2}\right)\end{array}$ \\
\hline $\begin{array}{l}\Delta \mathrm{VO}_{2}(\text { peak-AT }) \\
(\mathrm{mL} / \mathrm{min} / \mathrm{kg})\end{array}$ & 0.52 & 0.20 & 0.49 & 0.49 \\
\hline $\mathrm{p}$ & $<0.0001$ & 0.146 & 0.0001 & 0.0001 \\
\hline \multicolumn{5}{|c|}{$\begin{array}{l}\mathrm{AT} \text { - anaerobic threshold; } \mathrm{CO} \text { - cardiac output; } \mathrm{HR} \text { - heart rate; } \mathrm{LCWi} \text { - left cardiac work index, peak - } \\
\text { value at peak exercise; rest - value at rest; } \mathrm{SV} \text { - stroke volume; } \mathrm{VO}_{2} \text { - oxygen uptake; } \Delta \text { - changes in } \\
\text { parameter between its measurements at rest, at peak exercise, and at the anaerobic threshold }\end{array}$} \\
\hline
\end{tabular}


Changes in individual parameter values at specific time points showed the following correlations: $\Delta \mathrm{VO}_{2}$ (peak-AT) showed correlations with $\triangle \mathrm{HR}$ (peak-AT), $\triangle \mathrm{CO}$ (peak-AT), and $\triangle \mathrm{LCWi}$ (peak-AT) $(\mathrm{R}=0.52, \mathrm{p}$ $<0.0001 ; \mathrm{R}=0.49, \mathrm{p}=0.0001$; and $\mathrm{R}=0.49, \mathrm{p}=0.0001$, respectively); $\Delta \mathrm{VO}_{2}$ (peak-rest) showed correlations with $\Delta \mathrm{HR}$ (peak-rest), $\Delta \mathrm{CO}$ (peak-rest), and $\Delta \mathrm{LCWi}$ (peak- rest) $(\mathrm{R}=0.47, \mathrm{p}<0.0001 ; \mathrm{R}=$ $0.41, p=0.002$; and $R=0.43, p=0.001$, respectively). Neither the absolute $S V$ values nor $\Delta S V$ showed any correlation with the corresponding absolute $\mathrm{VO}_{2}$ and $\Delta \mathrm{VO}_{2}$ values in the total exercise period or in the period between AT and peak exercise. There was also no correlation between LVEF and peak $\mathrm{VO}_{2}$, peak SV, peak CO, or peak LCWi values.

\section{Discussion}

Our study findings suggest that ICG can be useful in assessing individual cardiovascular hemodynamic response to exercise in CAD patients in the early post-revascularization period. Unlike CPET, ICG illustrates different patterns of change in the parameters that characterize the function of the heart as a pump. The changes in HR and SV contributed to a various extent towards an exercise-induced increase in $\mathrm{CO}$, which may be clinically relevant.

The patients form this study group, who were assessed during early post-revascularization period, exhibited an exercise capacity (mean peak $\mathrm{VO}_{2}=18.2 \mathrm{~mL} / \mathrm{min} / \mathrm{kg}$ ) similar to that reported by Prado et al. [17] in patients after an acute coronary syndrome $(18.8 \mathrm{~mL} / \mathrm{min} / \mathrm{kg})$, but lower than that reported by Sparling et al. [18] in patients with stable CAD $(22.9 \mathrm{~mL} / \mathrm{min} / \mathrm{kg})$. Peak CO in our study group $(14.5$ $\mathrm{L} / \mathrm{min}$ ) was lower than that in healthy people $(15-25 \mathrm{~L} / \mathrm{min})$ [19], but higher than that in patients with HF and low exercise tolerance $(11.3 \mathrm{~L} / \mathrm{min})$ [20]. The increase in $\mathrm{CO}$ in our study group $(9.1 \mathrm{~mL} / \mathrm{min})$ was comparable with that in patients with stable CAD $(8.6 \mathrm{~mL} / \mathrm{min})$ [18] and higher than that in patients with $\mathrm{HF}$ with low exercise capacity $(7 \mathrm{~mL} / \mathrm{min})$ [20]. Also the SV of $36.3 \mathrm{~mL}$ measured in our patients was higher than that in patients with HF and low exercise capacity $(24 \mathrm{~mL})$ [20].

The relationship observed between the hemodynamic parameters measured via ICG and $\mathrm{VO}_{2}$ supports the supposition that ICG may reveal hemodynamic causes behind limited exercise capacity. The observed increase in both absolute and percentage $\mathrm{VO}_{2}$ values was associated with an increase in both absolute and percentage $\mathrm{CO}$ values. The increase in both $\mathrm{CO}$ and $\mathrm{HR}$ was relatively constant throughout the period of exercise, whereas the increase in SV after AT was usually insubstantial; in fact, nearly one-third of patients showed a decrease in SV after AT. The strongest correlations between the increase in $\mathrm{VO}_{2}$ and changes in hemodynamic parameters were observed during the intense workload period (peak-AT), which suggests that it is precisely during the later stage of exercise that the hemodynamic reaction affects the achieved peakVO $\mathrm{K}_{2}$ most. Moreover, we would like to emphasize that it was precisely in the period between achieving AT and peak exercise that the interindividual variation in SV values was considerably greater than that in HR values (Fig. 1). 
A relationship between low exercise capacity and the absence of SV increase during the final phase of the exercise test, as well as between low exercise capacity and low absolute SV values at peak exercise, have been reported in nonathletic adults [21] and in patients with hypertension [12], diastolic left ventricular dysfunction [22] and HF [11,20]. Moreover, a number of authors have emphasized the association between regular physical exercise and SV improvement [23, 24, 25].

The decrease in SV during the final phase of the exercise test observed in $31.5 \%$ of patients may suggest a persisting myocardial dysfunction $[7,26]$. Maintaining SV by patients with CAD is dependent mainly on the balance between preload, myocardial contractility, and afterload [6]. The abnormal SV reduction in response to exercise observed in the evaluated CAD patients post coronary revascularization, confirms Chaudhry's [7] hypothesis of a significant association between peak $\mathrm{VO}_{2}$ and both microcirculatory function and peripheral factors. The effect of vascular stiffness on limiting exercise tolerance in CAD patients should be also considered while interpreting our findings [27]. Such an effect is indirectly implied by the significant correlation between CPET intensity and LCWi values, which are an indicator of the left ventricular capacity to work against the afterload.

If the mechanisms responsible for an adequate increase in SV fail (e.g. in the case of exercise-related myocardial ischemia), a compensatory chronotropic response is activated $[7,8,9,10,11,26]$. Consequently, HR becomes the component chiefly responsible for generating adequate $\mathrm{CO}$ during strenuous exercise. However, this comes at the expense of higher oxygen consumption [28]. In our study group it was also $\mathrm{HR}$, and not $\mathrm{SV}$, that showed a significant correlation with $\mathrm{VO}_{2}$. Nonetheless, a lack of linear correlation of selected hemodynamic parameters (particularly SV) does not rule out their clinical importance irrespective of $\mathrm{VO}_{2}$ values. Elucidating these issues requires further, well methodologically designed, studies. Our study demonstrated no correlation between LVEF and either $\mathrm{VO}_{2}$ or hemodynamic parameters, which is consistent with reports by other authors $[29,30]$.

We would like to emphasize the response to exercise in terms of LCWi, considered to be a strong predictor of cardiovascular risk in HF patients [31]. In our study group the mean peak LCWi was $12.1 \mathrm{~kg}{ }^{\star} \mathrm{m} / \mathrm{m}^{2}$, which was a somewhat higher value than that reported by Myers et al. [31] in HF patients (10.4 $\mathrm{kg} \mathrm{m}^{\star} / \mathrm{m}^{2}$ ). The absolute peakLCWi value and changes in LCWi during exercise showed significant correlations with peakVO${ }_{2}$ and $\Delta \mathrm{VO}_{2}$, with the strength of these correlations comparable to that of the correlations observed between $\mathrm{VO}_{2}$ and $\mathrm{CO}$. LCWi was distinct among the evaluated parameters, as it showed more dynamic changes during the peak-AT period. While interpreting these findings it is important to bear in mind that Lewicki et al. demonstrated a dynamic reaction of LCWi values to changes in the parameters that determine myocardial contractility [32]. This confirms the hypothesis that LCWi reflects the ability of the left ventricle to cope with the workload associated with increasing exercise intensity.

\section{Clinical implications}


A noninvasive assessment of the hemodynamic profile during exercise in CAD patients provides additional, clinically important data on the factors that determine exercise capacity. Analysis of absolute values and trends in the changes of individual hemodynamic parameters may, in some cases, help identify the underlying causes of low exercise tolerance. Providing the possibility of assessing the profile of SV changes in addition to just assessing HR, the most commonly monitored parameter during exercise (e.g. sports training), may be useful in planning patient rehabilitation and identifying the causes of poor tolerance of training workloads. If CPET is unavailable, supplementing a traditional exercise test with ICG may be useful, with peak $\mathrm{CO}$ and LCWi values serving as indirect objective indicators of exercise capacity. The prognostic value of the parameters evaluated via ICG in this group of patients is still unknown; however, the results of our study encourage further research into this topic.

\section{Limitations}

The limitations of our study were the relatively small sample size and patient heterogeneity resulting from various comorbidities that may affect exercise capacity. Moreover, we assessed neither the patients' prerevascularization levels of exercise, nor the course of the coronary events preceding patient qualification for cardiac rehabilitation. Our assessments did not include any data on the level of patient motivation to complete the exercise test.

\section{Conclusions}

Impedance cardiography is a reliable method of assessing the cardiovascular response to exercise in patients with coronary disease. Some ICG parameters show definite correlations with measures of cardiovascular capacity of proven clinical utility, such as peak $\mathrm{VO}_{2}$. Thanks to the possibility of monitoring the pattern of cardiovascular response to exercise, ICG may be useful in further research in this area.

\section{Abbreviations}

AT anaerobic threshold

BMI body mass index

CAD coronary artery disease

CO cardiac output

COPD chronic obstructive pulmonary disease

CPET cardiopulmonary exercise testing

DBP diastolic blood pressure

eGFR estimated glomerular filtration rate 
HF heart failure

HR heart rate

ICG impedance cardiography

LCWi left cardiac work index

LVEF left ventricular ejection fraction

$\mathrm{O}_{2}$ Pulse oxygen pulse

peak \% pred predicted values at peak exercise

pred $\mathrm{VO}_{2}$ predicted value of $\mathrm{VO}_{2}$

RER respiratory exchange ratio

SBP systolic blood pressure

SV stroke volume

VE $/ \mathrm{VCO}_{2}$ slope ventilation-to-carbon dioxide output

$\mathrm{VO}_{2}$ oxygen uptake

$\mathrm{VO}_{2} / \mathrm{WR}$ work rate

$\Delta \mathrm{VO}_{2}$ changes in oxygen output

\section{Declarations}

\section{Ethics approval and consent to participate}

The study was conducted in accordance with the principles of Good Clinical Practice and Declaration of Helsinki. The study protocol had been approved by the local Bioethics Committee (approval No. 14/WIM/2014). Each patient provided a written informed consent to participate in the study.

\section{Consent for publication}

Not applicable.

\section{Availability of data and materials}

The datasets used and analyzed during the current study are available from the corresponding author on reasonable request. Data that supports the findings (demographic information and exercise test, ICG and 
other medical test results) were collected from medical records, and so are not publicly available. Data are however available from the authors upon reasonable request and with permission of Military Institute of Medicine.

\section{Competing interests}

None of the authors disclose any conflicts of interest regarding this manuscript.

\section{Funding}

The study was supported by the Ministry of Science and Higher Education/Military Institute of Medicine, Warsaw, Poland (grant no 336/WIM).

\section{Authors' contributions}

Conception and design: M.K., P.K.; Administrative support: K.P.; Provision of study materials or patients: M.K., K.G.; Collection and assembly of data: M.K.; Data analysis and interpretation: M.K.,P.K.; Manuscript writing: All authors; Final approval of manuscript: All authors.

\section{Acknowledgements}

Not applicable.

\section{References}

1. Kavanagh T, Mertens DJ, Hamm LF, Beyene J, Kennedy J, Corey P, et al. Prediction of long-term prognosis in 12169 men referred for cardiac rehabilitation. Circulation. 2002;106(6):666-71. https://doi:10.1161/01.cir.0000024413.15949.ed

2. Kavanagh T, Mertens DJ, Hamm LF, Beyene J, Kennedy J, Corey P, et al. Peak oxygen intake and cardiac mortality in women referred for cardiac rehabilitation. J Am CollCardiol. 2003;42(12):213943. https://doi:10.1016/j.jacc.2003.07.028

3. Ross R, Blair SN, Arena R, Church TS, Després JP, Franklin BA, et al. Importance of Assessing Cardiorespiratory Fitness in Clinical Practice: A Case for Fitness as a Clinical Vital Sign: A Scientific Statement From the American Heart Association. Circulation. 2016;134(24):e653-99. https://doi:10.1161/CIR.0000000000000461

4. Hung RK, Al-Mallah MH, McEvoy JW, Whelton SP, Blumenthal RS, Nasir K, et al. Prognostic value of exercise capacity in patients with coronary artery disease: the FIT (Henry Ford Exerclse Testing) project. Mayo Clin Proc. 2014;89(12):1644-54. https://doi:10.1016/j.mayocp.2014.07.011

5. Higginbotham MB, Coleman RE, Jones RH, Cobb FR. Mechanism and significance of a decrease in ejection fraction during exercise in patients with coronary artery disease and left ventricular dysfunction at rest. J Am CollCardiol. 1984;3(1):88-97. https://doi:10.1016/s0735-1097(84)80434-9 
6. Higginbotham MB, Morris KG, Williams RS, McHale PA, Coleman RE, Cobb FR. Regulation of stroke volume during submaximal and maximal upright exercise in normal man. Circ Res. 1986;58(2):28191. https://doi:10.1161/01.res.58.2.281

7. Chaudhry S, Arena R, Bhatt DL, Verma S, Kumar N. A practical clinical approach to utilize cardiopulmonary exercise testing in the evaluation and management of coronary artery disease: a primer for cardiologists. CurrOpinCardiol. 2018;33(2):168-77.

https://doi:10.1097/HC0.0000000000000494

8. Chaudhry S, Arena R, Wasserman K, Hansen JE, Lewis GD, Myers J, et al. Exercise-induced myocardial ischemia detected by cardiopulmonary exercise testing. Am J Cardiol. 2009;103(5):6159. https://doi:10.1016/j.amjcard.2008.10.034

9. Chaudhry S, Arena RA, Hansen JE, Lewis GD, Myers JN, Sperling LS, et al. The utility of cardiopulmonary exercise testing to detect and track early-stage ischemic heart disease Mayo Clin Proc. 2010;85(10):928-32. https://doi:10.4065/mcp.2010.0183

10. Smarż K, Jaxa-Chamiec T, Chwyczko T, Główczyńska R, Jegier A, Niedoszytko P, et al. Cardiopulmonary exercise testing in adult cardiology: expert opinion of the Working Group of Cardiac Rehabilitation and Exercise Physiology of the Polish Cardiac Society. Kardiol Pol. 2019;77(78):730-56. https://doi:10.33963/KP.14889

11. Belardinelli R, Ciampani N, Costantini C, Blandini A, Purcaro A. Comparison of impedance cardiography with thermodilution and direct Fick methods for noninvasive measurement of stroke volume and cardiac output during incremental exercise in patients with ischemic cardiomyopathy. Am J Cardiol. 1996;77(15):1293-301. https://doi:10.1016/s0002-9149(97)89153-9

12. Kurpaska M, Krzesiński P, Gielerak G, Uziębło-Życzkowska B, Banak M, Piotrowicz K, et al. Multiparameter assessment of exercise capacity in patients with arterial hypertension. Clin Exp Hypertens. 2019;41(7):599-606. https://doi:10.1080/10641963.2018.1523917

13. Kurpaska M, Krzesiński P, Gielerak G, Uziębło-Życzkowska B, Banak M, Stańczyk A, et al. Exercise impedance cardiography reveals impaired hemodynamic responses to exercise in hypertensives with dyspnea. Hypertens Res. 2019;42(2):211-22. https://doi:10.1038/s41440-018-0145-y

14. Ponikowski P, Voors AA, Anker SD, Bueno H, Cleland JGF, Coats AJS, et al. 2016 ESC Guidelines for the diagnosis and treatment of acute and chronic heart failure: The Task Force for the diagnosis and treatment of acute and chronic heart failure of the European Society of Cardiology (ESC)Developed with the special contribution of the Heart Failure Association (HFA) of the ESC. Eur Heart J. 2016;37(27):2129-200. https://doi:10.1093/eurheartj/ehw128

15. Balady GJ, Arena R, Sietsema K, Myers J, Coke L, Fletcher GF, et al. Clinician's Guide to cardiopulmonary exercise testing in adults: a scientific statement from the American Heart Association. Circulation. 2010;122(2):191-225. https://doi:10.1161/CIR.0b013e3181e52e69

16. Wasserman K, Hansen JE, Sue DY, Stringer WW, Sietsema KE, Sun XG, et al. Clinical applications of cardiopulmonary exercise testings. In: Principles of exercise testing and interpretations: including 
pathophysiology and clinical applications. Philadelphia: Lippincott Williams \& Wilkins; 2012: 194234

17. Prado DM, Rocco EA, Silva AG, Rocco DF, Pacheco MT, Silva PF, et al. Effects of continuous vs interval exercise training on oxygen uptake efficiency slope in patients with coronary artery disease. Braz J Med Biol Res. 2016;49(2):e4890. https://doi:10.1590/1414-431X20154890

18. Sperling MP, Caruso FC, Mendes RG, Dutra DB, Arakelian VM, Bonjorno JC, et al. Relationship between non-invasive haemodynamic responses and cardiopulmonary exercise testing in patients with coronary artery disease. Clin Physiol Funct Imaging. 2016;36(2):92-8. https://doi:10.1111/cpf.12197

19. Górski J, Fizjologiczne podstawy wysiłku fizycznego. Warszawa: PZWL; 2006

20. Fukuda T, Matsumoto A, Kurano M, Takano H, lida H, Morita T, et al. Cardiac output response to exercise in chronic cardiac failure patients. Int Heart J. 2012;53(5):293-8. https://doi.org/10.1536/ihj.53.293

21. Gledhill N, Cox D, Jamnik R. Endurance athletes' stroke volume does not plateau: major advantage is diastolic function. Med Sci Sports Exerc. 1994;26(9):1116-21. PMID: 7808245

22. Palmieri V, Russo C, Palmieri EA, Arezzi E, Pezzullo S, Minichiello S, et al. Isolated left ventricular diastolic dysfunction: implications for exercise left ventricular performance in patients without congestive heart failure. J Am Soc Echocardiogr. 2006;19(5):491-8. https://doi:10.1016/j.echo.2005.12.011

23. Lee BA, Oh DJ. The effects of long-term aerobic exercise on cardiac structure, stroke volume of the left ventricle, and cardiac output. J ExercRehabil. 2016;12(1):37-41. Published 2016 Feb 1. https://doi:10.12965/jer.150261

24. Murugesan J, Giuseppe C, Ferdinando I, Maurizio V, Calogero F. The relationship between central hemodynamics and systemic vascular resistance in patients with heart failure at cardiac rehabilitation.Annals of Physical and Rehabilitation Medicine. 2014; 57 (S1):292. https://doi:10.1016/j.rehab.2014.03.1063

25. Futami M, Fujimi K, Ueda T, Matsuda T, Fujita M, Kaino K, et al. Cardiac rehabilitation in patients with cardiovascular disease leads various hemodynamic parameters obtained using simple non-invasive tests to their appropriate levels. Int J Cardiol Heart Vasc. 2017;17:23-9. https://doi:10.1016/j.ijcha.2017.10.001.

26. Belardinelli R, Lacalaprice F, Tiano L, Muçai A, Perna GP. Cardiopulmonary exercise testing is more accurate than ECG-stress testing in diagnosing myocardial ischemia in subjects with chest pain. Int $\mathrm{J}$ Cardiol. 2014;174(2):337-42. https://doi:10.1016/j.ijcard.2014.04.102

27. Alves AJ, Oliveira NL, Lopes S, Ruescas-Nicolau MA, Teixeira M, Oliveira J, et al. Arterial Stiffness is Related to Impaired Exercise Capacity in Patients With Coronary Artery Disease and History of Myocardial Infarction. Heart Lung Circ. 2019;28(11):1614-21. https://doi:10.1016/j.hlc.2018.08.023

28. Kyröläinen H, Pullinen T, Candau R, Avela J, Huttunen P, Komi PV. Effects of marathon running on running economy and kinematics. Eur J ApplPhysiol 2000;82:297-304. 
https://doi:10.1007/s004210000219

29. Hasselberg NE, Haugaa KH, Sarvari SI, Gullestad L, Andreassen AK, Smiseth OA, et al. Left ventricular global longitudinal strain is associated with exercise capacity in failing hearts with preserved and reduced ejection fraction. Eur Heart J Cardiovasc Imaging. 2015;16(2):217-24. https://doi:10.1093/ehjci/jeu277

30. Lapu-Bula R, Robert A, De Kock M, D'Hondt AM, Detry JM, Melin JA, et al. Relation of exercise capacity to left ventricular systolic function and diastolic filling in idiopathic or ischemic dilated cardiomyopathy. Am J Cardiol 1999;83(5): 728-34. https://doi:10.1016/s0002-9149(98)00979-5

31. Myers J, Christle JW, Tun A, Yilmaz B, Moneghetti KJ, Yuen E, et al. Cardiopulmonary Exercise Testing, Impedance Cardiography, and Reclassification of Risk in Patients Referred for Heart Failure Evaluation. J Card Fail. 2019;25(12):961-8. https://doi:10.1016/j.cardfail.2019.08.013

32. Lewicki L, Fijalkowska M, Karwowski M, Siebert K, Redlarski G, Palkowski A, et al. The non-invasive evaluation of heart function in patients with an acute myocardial infarction: The role of impedance cardiography. Cardiol J. 2019;10.5603/CJ.a2019.0098. https://doi:10.5603/CJ.a2019.0098

\section{Figures}



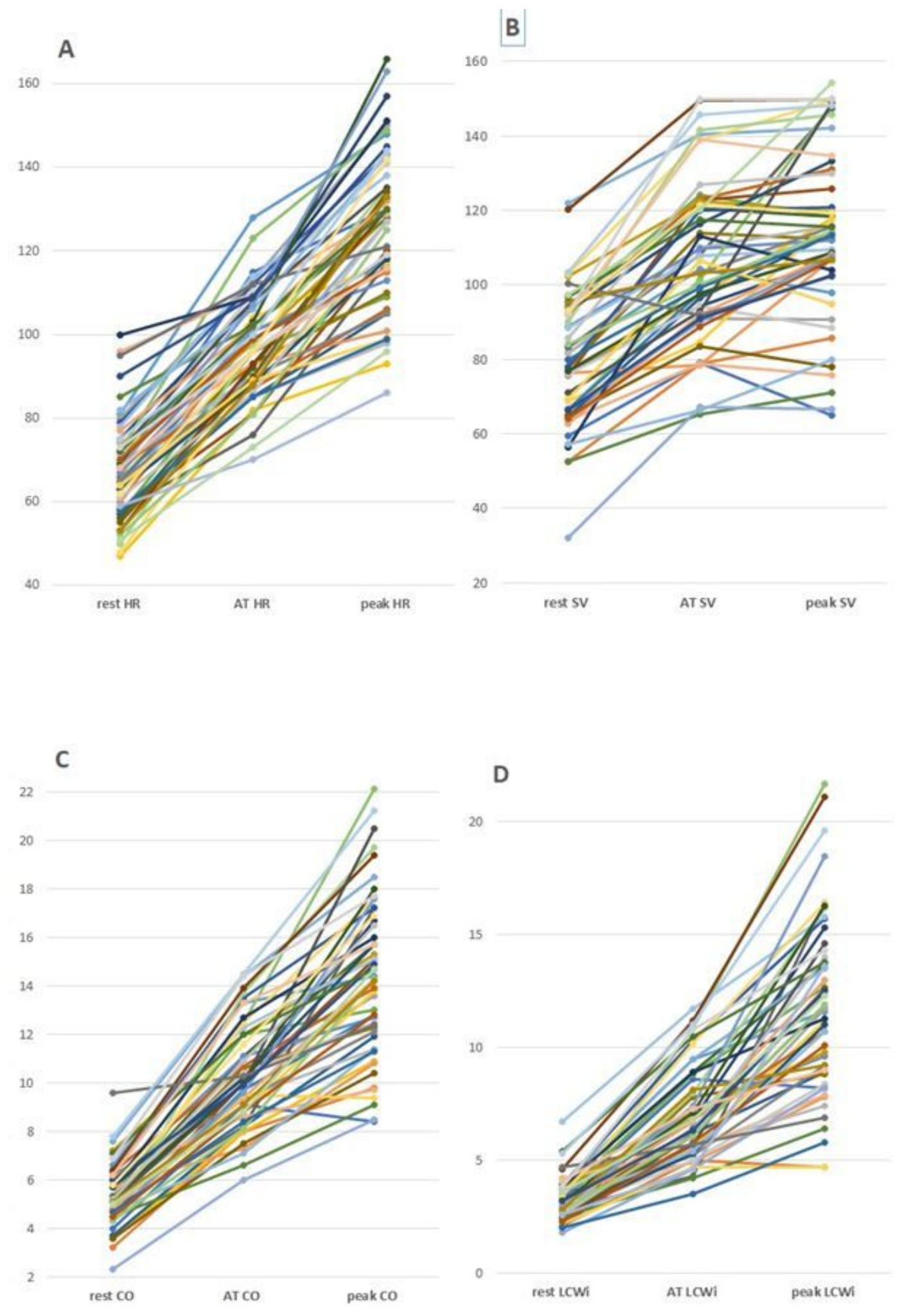

Figure 1

Individual trends of selected hemodynamic parameters: chart A - heart rate (HR [bpm]), chart B - stroke volume (SV $[\mathrm{mL}])$, chart $\mathrm{C}$ - cardiac output (CO $[\mathrm{mL} / \mathrm{min}])$, chart $\mathrm{D}$ - left cardiac work index (LCWi $\left.\left[\mathrm{kg}{ }^{\star} \mathrm{m} / \mathrm{m} 2\right]\right)$. 